\title{
Wissadula Medik. (Malvaceae) no Brasil: novas espécies e combinação
}

\author{
Massimo G. Bovini ${ }^{1,2}$
}

Recebido em 9/06/2009. Aceito em 4/03/2010

RESUMO - (Wissadula Medik. (Malvaceae) no Brasil: novas espécies e combinação). Duas novas espécies e uma nova combinação são apresentadas para o gênero Wissadula (Malvaceae): Wissadula delicata Bovini, W. krapovickasiana Bovini e Wissadula caribea (DC.) Bovini, respectivamente, além de novos sinônimos. Para as espécies apresentadas, são fornecidas descrições, ilustrações e chaves de reconhecimento para distingui-las das espécies relacionadas. Palavras-chave: Brasil, IUCN, Wissadula, Malvaceae

ABSTRACT - (Wissadula Medik. (Malvaceae) in Brazil: new species and combination). Two new species and a new combination are presented for genus Wissadula (Malvaceae): Wissadula krapovickasiana Bovini, W. delicata Bovini and Wissadula caribea (DC.) Bovini, respectively, plus new synonyms. Descriptions, illustrations and keys to distinguish these species from similar species are supplied.

Key words: Brazil, IUCN red list, Wissadula, Malvaceae

\section{Introdução}

O gênero Wissadula Medik., amplamente distribuído na região neotropical, é reconhecido principalmente pela presença de uma constricção no mericarpo, separando as três sementes em duas lojas, duas colaterais superiores e uma inferior (Fryxell 1997), mas sem a presença da endoglossa. Dando continuidade ao estudo do gênero Wissadula no Brasil (Bovini 2009), duas novas espécies são descritas e uma nova combinação realizada.

\section{Resultados e discussão}

\section{Wissadula delicata Bovini, sp. nov.} Fig. 1

Suffrutex gracilis. Rami erecti, fere glabri. Lamina folii deltoidea ad leviter cordiformem, apice rotundato ad rare acutum, margine integra interdum serrata. Corolla ca. $2 \mathrm{~mm}$ diam., fulva, sine macula.

Subarbusto, ca. $1 \mathrm{~m}$ alt. Ramos eretos, glabrescentes quando adultos, pubescentes quando jovens, tricomas fasciculados e multiradiado-estipitados. Estípulas ca. $1 \mathrm{~mm}$ compr., lineares, caducas, livres, tomentosas, tricomas fasciculados ferrugíneos. Folhas com pecíolos 0,5-2 cm compr., indumento e tricomas iguais aos ramos adultos; lâmina foliar 1,5-3,5 x 0,7-2 cm, levemente verde discolor, membranácea, deltóide, rara levemente cordiforme, base truncada a subcordada, ápice arredondado a raro agudo, margem inteira, por vezes serrilhada no mesmo indivíduo, ciliada; face adaxial pubérula, tricomas simples, glandulares, fasciculados; face abaxial velutina, tricomas alvacentos, fasciculados. Sinflorescências frondo-bracteosas, piramidais, laxas; coflorescências em duplo-racemos, 4-6 cm compr.; antopódios ca. $2 \mathrm{~cm}$ compr., tomentoso, tricomas glandulares e fasciculados; brácteas persistentes, lineares, aos pares, ca. $1 \mathrm{~mm}$ compr., tricomas simples, glandulares. Flores com pedicelo ca. 8 mm compr., indumento e tricomas iguais ao antopódio; cálice ca. $5 \mathrm{~mm}$ compr., lobado até a porção mediana; face abaxial tomentosa, tricomas fasciculados, ferrugíneos; face adaxial vilosa, tricomas simples longos; corola ca. 2 cm diâm., amarela, sem mácula; pétala vilosa na base da margem, tricomas fasciculados-estipitados; filetes parcialmente concrescidos ca. $1 \mathrm{~mm}$ compr., formando um tubo estaminal com tricomas simples, hialinos, e porção livre dos estames aprox. $3 \mathrm{~mm}$ compr., raros tricomas hialinos, simples; ovário 4 locular, 3 óvulos por lóculo; estilete ca. $4 \mathrm{~mm}$ compr. Esquizocarpos ca. $1 \mathrm{~cm}$ diâm., pubérulo, 4 mericarpos 8-9 x 3-4 mm, constrição evidente, tricomas hialinos, fasciculados, uniformemente distribuídos, freqüentemente fasciculados, aristas ca. $1 \mathrm{~mm}$ compr.; sementes 3, ca. $2 \mathrm{~mm}$ compr., hirtelas, tricomas simples, longos, lanosas na região do hilo.

Tipo: Brasil. Mato Grosso do Sul: Ladário, 08/IX/1984, fl, C.A.Conceição 1569 (Holótipo RB, isótipo CTES).

Parátipos: BRASIL. Mato Grosso do Sul: Corumbá, margem do Paraguai, 01/X/1953, bt., E. Pereira et al. 147 (RB); morro da região do Castelo, $18^{\circ} 35^{\prime} 27,6^{\prime} \mathrm{S}$ e $57^{\circ}$ 32' 39,4"W, 17/X/2002, fr., I. M. Bortolotto et al. 1117 (COR, CTES).

Distribuição geográfica: conhecida somente pelas coleções do Estado de Mato Grosso do Sul.

Wissadula delicata destaca-se das demais espécies do gênero, principalmente aquelas ocorrentes no pantanal brasileiro, por apresentar lâminas foliares de pequenas medidas em relação as espécies correlatas, a forma deltóide, rara levemente cordiformes e margem inteira e serreada no mesmo indivíduo, e a corola com ca. $2 \mathrm{~cm}$ diâmetro, considerada de grande dimensão para o gênero. Está relacionada com $W$. paraguariensis, mas a ausência da mácula vinosa na fauce e dos tricomas fasciculados concentrados na soldadura dos carpelos e região distal do mericarpo em $W$. delicata, as distinguem.

\footnotetext{
Instituto de Pesquisas Jardim Botânico do Rio de Janeiro, Diretoria de Pesquisas, Rio de Janeiro, RJ, Brasil

2 Autor para correspondência: mbovini@jbrj.gov.br
} 


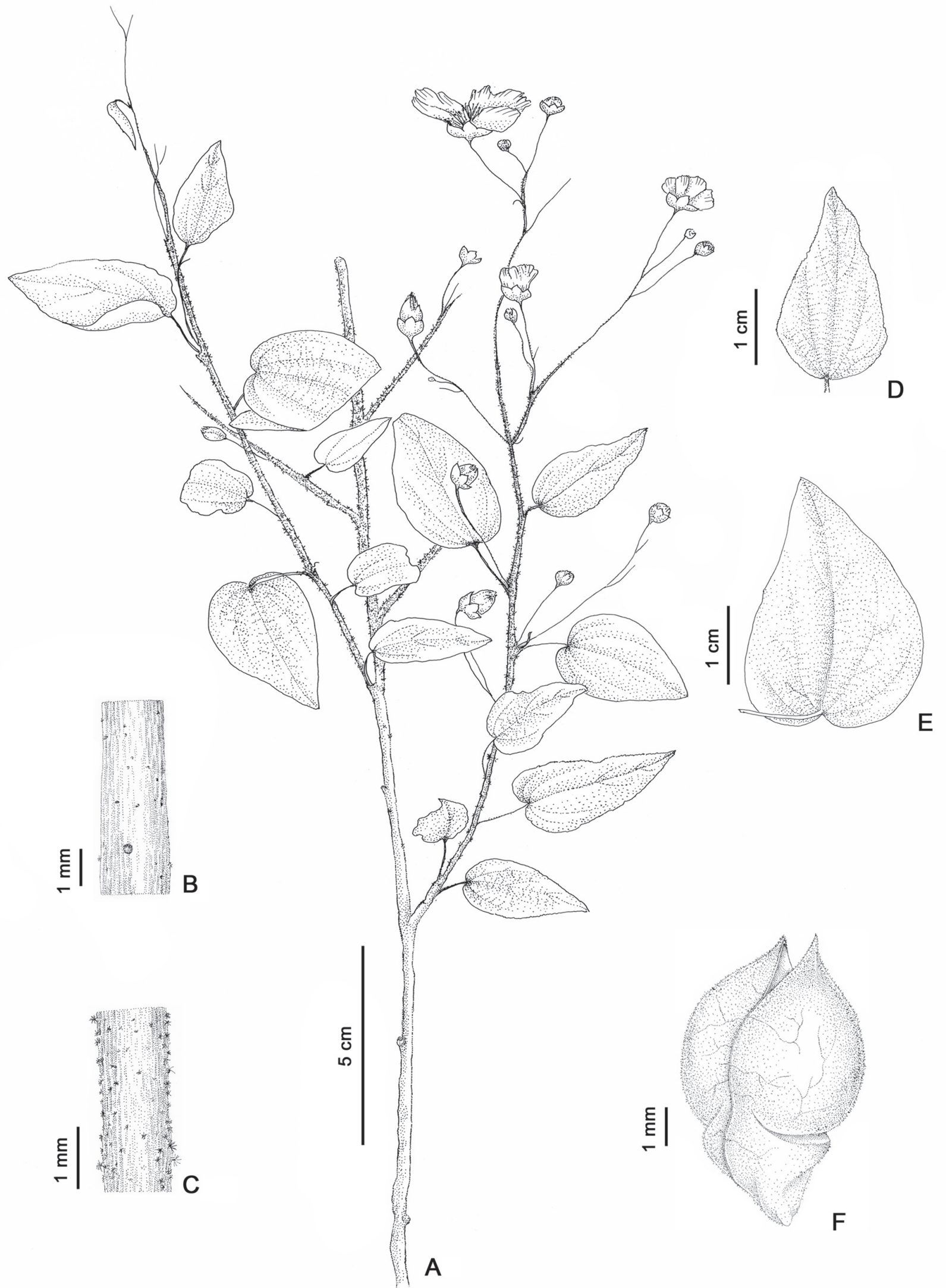

Figura 1. Wissadula delicata Bovini. A. Ramo com flores; B-C. Parte dos ramos jovens e adultos, respectivamente; D-E. Folhas; F. Mericarpo, vista laterodorsal (Conceição 1569). 
Apenas duas coletas são registradas para esta espécie. Devido à baixa amostragem, torna-se imprecisa uma avaliação de seu risco de extinção e a espécie deverá ser enquadrada na categoria Deficientes de Dados (IUCN 2001).

Devido ao hábito bastante delicado da espécie, o epíteto específico caracteriza o aspecto da planta.

\section{Wissadula krapovickasiana Bovini, sp. nov.} Fig. 2

Suffrutex. Stipulae lineares ad lanceolatas, 2-3 mm longae. Lamina folii base cordata, apice acuto. Schizocarpium 4-mericarpiis, constrictione manifesta, tomentosum, trichomata fasciculata, hyalina.

Subarbusto. Ramos eretos, tomentosos quando adultos, tricomas hialinos, fasciculados e fasciculado-estipitados, indumento menos denso quando jovens, tricomas hialinos, fasciculados, raríssimos tricomas simples. Estípulas 2-3 $\mathrm{mm}$ compr., lineares a lanceoladas, caducas, livres, tomentosas, tricomas fasciculados, raros simples. Folhas com pecíolos 1,5-3,5 cm compr., indumento e tricomas iguais aos ramos adultos; lâmina foliar 3-8,5 x 2,7-6,5 cm, levemente verde discolor, membranácea a cartácea, cordiforme, base cordada, ápice agudo, às vezes, levemente obtuso, margem inteira, ciliada; face adaxial pubérula, tricomas hialinos, simples, glandulares, fasciculados, raros multiradiados; face abaxial velutina, tricomas alvacentos, multiradiadoestipitados. Sinflorescências frondo-bracteosas, piramidais, laxas; coflorescências em duplo-racemos, 25-30 cm compr.; eixos acessórios reduzidos, 2(-3) flores; antopódios 1,8-2 $\mathrm{cm}$ compr., pubescentes, tricomas fasciculados e glandulares diminutos; brácteas caducas, lineares a lanceoladas, aos pares, ca. $1 \mathrm{~mm}$ compr., tricomas fasciculados. Flores com pedicelo 10-13 mm compr., tomentoso, indumento e tricomas iguais ao antopódio; cálice 5-6 mm compr., lobado até a porção mediana, acrescente no fruto, lobado pouco abaixo da região mediana; face abaxial tomentosa, tricomas fasciculados e glandulares diminutos, face adaxial pubérula, raríssimos tricomas simples, longos; corola 10-11 mm diâm., amarela, sem mácula; pétala vilosa na base da margem, tricomas fasciculado-estipitados; filetes parcialmente concrescidos ca. $1 \mathrm{~mm}$ compr., formando um tubo estaminal com raros tricomas hialinos, simples e fasciculado-estipitados, e porção livre dos estames aprox. $2 \mathrm{~mm}$ compr., raros tricomas hialinos, simples; ovário 4 (-5) locular, 3 óvulos por lóculo; estilete ca. $4 \mathrm{~mm}$ compr. Esquizocarpos 1,1-1,2 cm diâm., 4 mericarpos 8-9 x 4-5 $\mathrm{mm}$, constrição evidente, tomentosos, tricomas hialinos, fasciculados, uniformemente distribuídos, aristas ca. $1 \mathrm{~mm}$ compr; sementes 3, ca. $3 \mathrm{~mm}$ compr., hirtelas, tricomas simples, longos, lanosas na região do hilo.

Tipo: Brasil. Mato Grosso do Sul: Corumbá, Jacadigo, Fazenda Coqueiro, 23/X/1988, fl, A. Pott et V.J.Pott 4446 (Holótipo CPAP; isótipo CTES; foto do holótipo RB).

Parátipos: BRASIL. Mato Grosso do Sul: Porto Murtinho, córrego Capivara, 17/III/1985, fl., G. Hatschbach et al. 49213 (CTES, MBM); estrada Bocaiúva 2, beira da estrada, 17/ IV/2005, fl.fr., D. Noguehi et al. 258 (CGMS). PARAGUAI. Alto Paraguay, Palma Chicas, Cerro Celina, 28/VI/1977, fl.fr., A. Krapovickas et A. Schinini 32784 (CTES). Concepcion, 5 km N de Loreto, 180 m s.m., 17/XII/ 1983, fl.fr., R. Vanni et al. 384 (CTES). La Cordillera, Ypacari, 26/V/1964, fl.fr., $A$. Krapovickas et C.L.Cristóbal 11487 (CTES).

Distribuição geográfica: Paraguai e Brasil, onde ocorre até o momento, somente no estado de Mato Grosso do Sul.

Wissadula krapovickasiana é caracterizada pela base cordada da lâmina foliar, tamanho da estípula (2-3 mm compr.) e o indumento tomentoso do fruto com 4 mericarpos. É muito semelhante a $W$. paraguariensis, espécie também da região do pantanal, mas essa última se diferencia de W. krapovickasiana pela base truncada da lâmina foliar e principalmente o indumento pubescente dos frutos, fornecendo-lhe uma aparência mais lustrosa, especialmente na região de soldadura dos carpelos e na região distal.

W. krapovickasiana encontra-se até o momento, na região do Pantanal brasileiro e paraguaio, em área antropizada. De acordo com os critérios propostos pela IUCN (2001), a espécie enquadra-se na categoria vulnerável (VU, B2ab(iii)).

$\mathrm{O}$ epíteto específico homenageia o emérito especialista argentino em Malvaceae, Dr. Antonio Krapovickas.

Chave para reconhecimento de $W$. delicata e $W$. krapovickasiana da espécie afim

1. Lâmina foliar com base frequentemente truncada; corola com mácula vinosa na fauce; esquizocarpo 4-5 mericarpos com tricomas fasciculados concentrados na soldadura dos carpelos e região distal do mericarpo W. paraguariensis

1. Lâmina foliar com base truncada a subcordada ou sempre cordada; corola sem mácula vinosa na fauce; esquizocarpo 4 mericarpos com tricomas fasciculados uniformemente distribuídos.

2. Lâmina foliar deltóide, rara levemente cordiforme, ápice arredondado a raro agudo, margem inteira, por vezes serreada no mesmo indivíduo; corola ca. 2 cm diâm W. delicata

2. Lâmina foliar cordiforme, ápice geralmente agudo, às vezes levemente obtuso, margem inteira; corola ca. 1-1,1 cm diâm. 


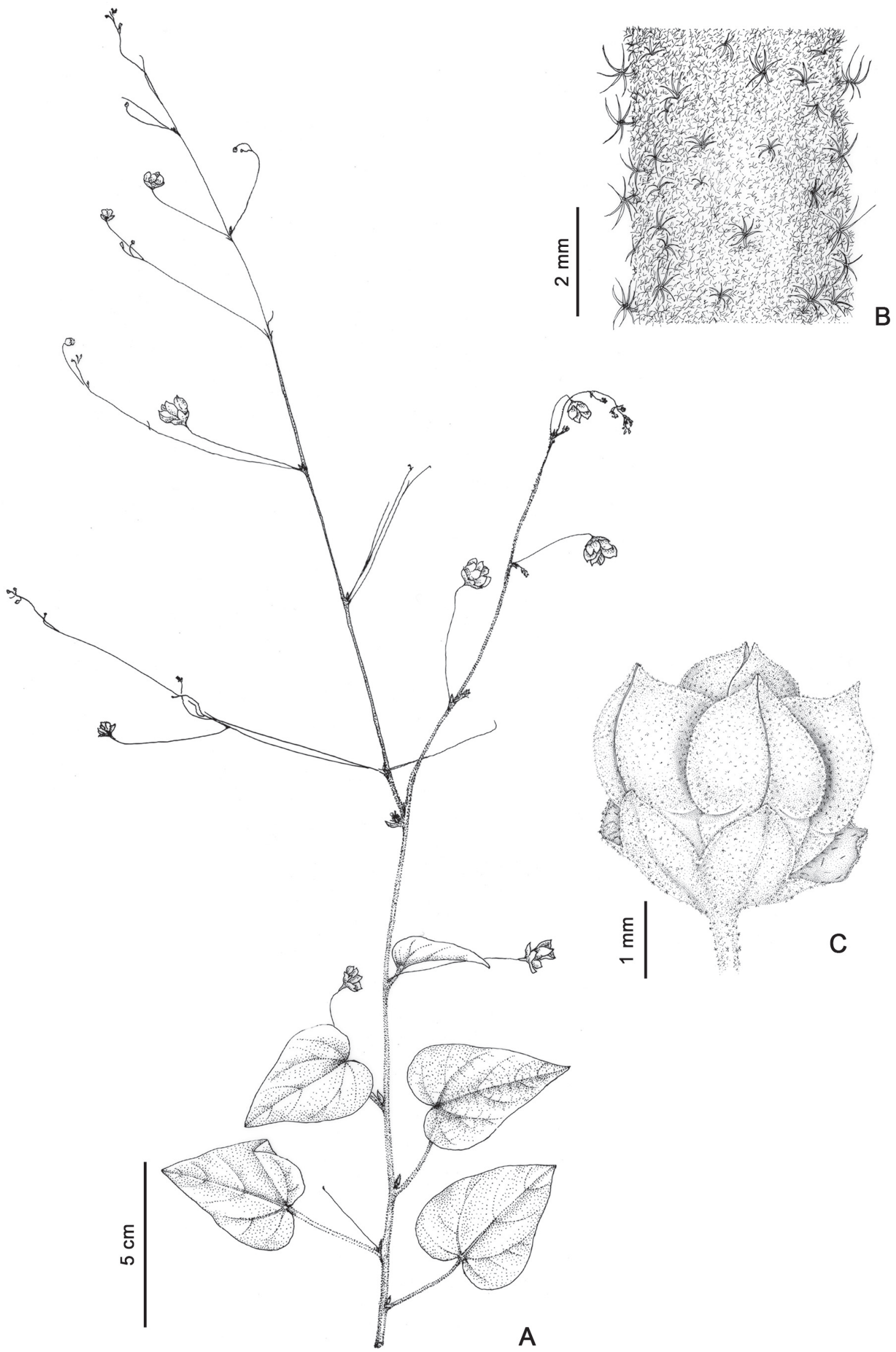

Figura 2. Wissadula krapovickasiana Bovini. A. Ramo com botões e frutos; B. Parte do ramo evidenciando os tricomas; C. Fruto (Krapovickas et al. 32784). 
Wissadula caribea (DC.) Bovini, nov. comb. et nov. stat. Sida periplocifolia var. caribea DC., Prod. I, 468. 1824. Tipo: Jamaica, localidade desconhecida, s.d., Swartz 260? (Lectótipo, aqui designado, S!).

W. periplocifolia (L) C.Presl. var. antillarum R. E. Fr. f. macrophylla R. E. Fr., Kungl. Svenska Vetenskapsakad. Handl. 43(4):35. 1908. Tipo: Porto Rico, Cabo-Rojo circa hacienda Carmelita, 13/I/ 1885, Sintenis 803 (Lectótipo aqui designado US!). syn. nov.

W. periplocifolia (L) C.Presl. var. antillarum R.E.Fr. f. microphylla R.E.Fr., Kungl. Svenska Vetenskapsakad. Handl. 43(4):35. 1908. Tipo: Cuba, localidade não informada, 1865, Wright 2050 pro parte (Lectótipo, aqui designado US!; isolectótipo NY!). syn. nov.

Ilustrações: Fries 1908, tab.1, fig. 4.

Material examinado: CUBA. Localidade não informada, 1865, Wright 2050 pro parte (US!; isolectótipo NY!); Sta. Clara, Cienfuegos, 1891, R. Combs 634 (K!). PORTO RICO. Cabo-Rojo circa hacienda Carmelita, 13/I/1885, Sintenis 803 (US!); roadside Yauco, 22/VI/1901, Underwood et Griggs 625 (NY!); Arroyo et Guayama, 12/X/1885, Sintenis 2243b (US!). BRASIL. Piauí: a 27 km W de Oeiras, BR-320, 08/IV/1983, fl.fr., A. Krapovickas 38771 (CTES). Ceará: s. proc., 27/ VI/1935, fl., F. Drouet 2380 (R). Aurora, sítio Soledade, 26/ VI/1941, fl., P. Bezerra s.no (CTES 50851). Maracanaú: Santo Antonio, E. E. P. T., I/1937, fl.fr., L. Barroso 01 (RB, RBR). Maranguape: ticket about açude Columinjuba, 09/X/1935, fr., F. Drouet 2584 (R). Pernambuco: Fernando de Noronha, V/1986, fl.fr., L. E. Melo Filho 5176 (R); em terrenos encapoeirados, 09/III/1993, fl.fr., L.P.Félix 5677 et al. (CTES, HST); Hotel de Trânsito, 20/XII/2002, fl.fr., A. M. Miranda 3252 (CTES, HST). Bahia: Governador Mangabeira: Barragem de Bananeiras, V/1980, fl.fr., "Pedra do Cavalo" 43 (RB); BR-101, próximo a represa Pedra do cavalo, 14/I/1997, fl.fr., M. M. Arbo 7215 (CTES). Uauá: caminho para o Distrito de Pilar, 29/III/2000, fl.fr., E. Saar 04 (ALCB, RB).

Distribuição geográfica: América Central e Brasil, onde ocorre nos estados do Piauí, Ceará, Pernambuco e Bahia.

Historicamente, alguns exemplares de $W$. periplocifolia, com folhas largo-cordiformes e flores solitárias e axilares, sempre foram base para descrição de novas variedades ou análises críticas quanto à circunscrição desses táxons (De Candolle 1824; Fries 1908). Em Fries (1908), o autor estabeleceu $W$. periplocifolia var. antillarum, caracterizando-a pelas "lamina ovato-triangulares ...; flores axillares solitarii vel inflorescentiis terminalibus minus laxis dispositi, ...", e referiu sua ocorrência como sendo restrita às Antilhas, mas estabelece apenas em nível de variedade, por não possuir muito material para uma análise mais criteriosa.

Entretanto, o exame de exemplares analisados por Fries em 1908 (ver relação dos tipos acima) com a variedade e forma típicas, revelou realmente não se tratar de $W$. periplocifolia, conforme Fries (1908) comentou. Coletas recentes, provenientes da região Nordeste brasileira, enquadram-se nas características descritas acima que estão perfeitamente de acordo com o protólogo da variedade antillarum. A ampliação da distribuição geográfica da espécie pode ser interpretada como uma expansão de uma faixa de ocorrência, a partir das Antilhas, englobando o Nordeste brasileiro. No que se refere ao tamanho das folhas, Fries (1908) ainda estabeleceu as formas microphylla e macrophylla, com base no comprimento e largura destas. No presente estudo, analisaram-se vários exemplares e pôde-se considerar a variação de tamanho das folhas, onde já no próprio protólogo essa variação é mínima.

Fries (1908), ao estabelecer $W$. periplocifolia var. antillarum, não consultou o trabalho de De Candolle (1824), que em Sida periplocifolia (atualmente W. periplocifolia) propõe três variedades com base na forma e indumento da folha: zeylanica, caribea e peruviana. Analisando a obra de De Candolle (1824), e considerando que foi o mesmo material (Swartz 260?) examinado por Fries em 1908, percebe-se a semelhança tanto do protólogo, como dos exemplares analisados da variedade caribea, de De Candolle com as da variedade antillarum, de Fries (1908).

No material de Swartz, o número 260 causa dúvida quanto a sua informação, ou é número de coleta ou número da coleção particular de Swartz. Quanto o termo "pro parte" no material Wright 2050, o coletor possui o mesmo número de coleta em outra coleção (UPS), determinada como $W$. excelsior. Fries (1908), quando descreve a nova forma macrophylla, percebe o engano de Wright e acrescenta o termo supra-citado.

Wissadula caribea é caracterizada por possuir lâminas membranáceas, as basais largo-cordiformes, sinflorescências axilares, reduzidas a mônades (flores solitárias), e esquizocarpos comumente com quatro mericarpos, raro cinco. Assemelha-se a $W$. periplocifolia, porém as lâminas foliares mais cartáceas e cinco mericarpos, nesta última as distinguem. Também se assemelha a $W$. fadyenii R. E. Fr., espécie que não ocorre no Brasil e que apresenta apenas uma semente por mericarpo.

Chave para reconhecimento de W. caribea e espécie afim

1. Lâmina foliar membranácea, basal largo-cordiforme e apical cordiforme; sinflorescências constituídas de mônades axilares W. caribea

1. Lâmina foliar semi-cartácea, todas geralmente cordiformes ou deltóides; sinflorescências constituídas de duplos-racemos, axilares ou terminais W. periplocifolia 


\section{Agradecimentos}

Aos curadores dos herbários CGMS, CPAP, CTES, MBM, pelo empréstimo do material.

\section{Referências bibliográficas}

Bovini, M.G. 2009. Uma nueva espécie y combinación em Wissadula (Malvaceae). Novon 19: 15-17.
De Candolle, A.P. 1824. Malvaceae. In: Prodromus systematis naturalis regni vegetabilis I. 429-474. Paris.

Fries, R.E. 1908. Entwurf einer Monographie der Gattungen Wissadula und Pseudabutilon. Kongl. Svenska Vetenskapsakad. Handl. 43(4): 1-114. Fryxell, P.A. 1997. The American genera of Malvaceae II. Brittonia 49(2): 204-269. International Union for Conservation of Nature and Natural Resources (IUCN). 2001. IUCN Red List categories and criteria, version 3.1. Gland, Switzerland and Cambridge, United Kingdom. http://www.iucn.org

Versão eletrônica do artigo em www.scielo.br/abb e http://www.botanica.org.br/acta/ojs 